\title{
SUCESSO E INOVAÇÃO NO MUNDO EMPRESARIAL PERSPECTIVA HISTÓRICA *
}

\author{
José Amado Mendes **
}

A fase histórica finessecular em que nos encontramos caracteriza-se, entre outros, pelos seguintes factores: ritmo acelerado das transformações socioeconómicas e culturais; crescente globalização da economia e da informação; intensa competitividade; e grande facilidade nas comunicações. Neste contexto, compreende-se que, embora o sucesso seja por muitos almejado, nem todos consigam atingi-lo. Ora, como a inovação tem constituído, precisamente, uma das vias para se alcançar o dito sucesso, justifica-se que se lhe dedique uma especial atenção. Mas, antes de prosseguir, convirá esclarecer o que deve entender-se pelo referido conceito.

Em sentido lato, «a inovação consiste na aplicação dos conhecimentos criados

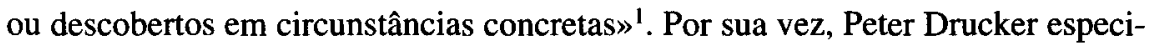
fica:

«A inovação sistemática consiste, pois, na procura organizada e intencional de mudanças, e [n]a análise sistemática das oportunidades que tais mudanças podem proporcionar à inovação económica e social» ${ }^{2}$.

Como se depreende do que fica exposto, trata-se de uma noção muito ampla que, de modo algum, se pode restringir à vertente tecnológica, a despeito de até agora - ter sido esta a perspectiva mais focada por diversos autores ${ }^{3}$. Como, a propósito, recorda igualmente $P$. Drucker: «A inovação não tem de ser técnica; na verdade, nem sequer tem de ser uma "coisa". Poucas inovações técnicas poderão competir, em termos de impacte, com inovações sociais como os jornais ou os seguros» ${ }^{4}$.

Relacionadas com a inovação - mas sem se confundirem com ela — podem referir-se a invenção, a montante, e a difusão, a jusante. Assim, enquanto «a invenção é uma ideia de uma nova aplicação da ciência e da tecnologia», a difusão «consiste em expandir o uso da inovação no grupo dos seus possíveis utilizadores» $»^{5}$.

Dada a importância do factor inovação e das suas numerosas implicações — no desenvolvimento, nível de vida e bem-estar dos povos —, é relativamente escasso

\footnotetext{
** Faculdade de Letras da Universidade de Coimbra; Instituto Universitário de Desenvolvimento e Promoção Social - Pólo de Viseu da Universidade Católica Portuguesa.
} 
o número de estudos sobre a temática. Com efeito, além de não se ter ainda desenvolvido uma teoria da inovação ${ }^{6}$ e de a investigação empírica sobre o tema ser relativamente recente - visto datar dos dois últimos decénios —, a ênfase dada a um dos vectores da inovação, isto é, à inovação tecnológica, como que tem feito olvidar outras facetas, não menos significativas, do fenómeno em causa. Refiro-me, por exemplo: à receptividade ou às resistências à inovação, bem como aos contextos socioeconómicos, educativos e culturais que a têm favorecido; à inovação como elemento decisivo da estratégia empresarial; aos diversos tipos de repercussões de actividades e/ou políticas estimuladoras da inovação. Mas, em que consiste a inovação? E como é que esta tem sido perspectivada, ao longo da história?

\section{INOVAÇÃO: POLISSEMIA E DIACRONIA DE UM CONCEITO}

Em todas as épocas se podem detectar inovações - inerentes, aliás, às próprias noções de progresso e de desenvolvimento - em maior ou menor número. Entre muitos outros exemplo, recordo: a cerâmica grega, a arquitectura e a calçada romana, o moinho hidráulico medieval, a imprensa - a partir de meados do século $\mathrm{XV}$ - , a máquina a vapor, com a revolução industrial, o automóvel, desde os anos $1890 \mathrm{e}$, mais recentemente, os equipamentos informáticos. Acrescente-se, contudo, que também noutros domínios - como a literatura, as artes plásticas ou a filosofia - se têm verificado fenómenos análogos de inovação.

Apesar deste "pano de fundo", subjacente à inovação - se perspectivada no longo prazo - , destacaram-se alguns períodos históricos: por um lado, devido a uma maior densidade de inovações, em curtos lapsos de tempo. É, neste sentido, que se pode falar de «cachos de inovações» ou mesmo de «revoluções»; por outro, em virtude de se ter verificado uma relação mais estreita - inclusive no tempo - entre a invenção, a inovação e a difusão de certas ideias, tecnologias ou métodos de organização ou de trabalho.

Por exemplo, na Renascença, muitas das invenções de Leonardo da Vinci (1452-1519) - que já foi considerado «o maior génio inventivo da nossa história» ${ }^{7}$ - não se transformaram em inovações, por falta de condições e contexto adequados. Sobre o assunto, já se afirmou o seguinte: «Há uma ideia empolgante - submarino, ou helicóptero, ou forja automática - em cada página dos seus cadernos de apontamentos. Mas nenhuma delas podia ser convertida em inovação com a tecnologia e os materiais de 1500 . Na realidade, nenhuma delas teria receptividade na sociedade e na economia desse tempo» ${ }^{8}$.

Entretanto, as condições foram-se alterando progressivamente. $O$ experiencialismo - dos nossos descobridores quinhentistas - viria a dar lugar ao experimentalismo; Descartes, com o seu Discurso do método (1637), contribuiu para a 
estruturação do método científico; e os enciclopedistas franceses chamaram a atenção para a "dignidade" das artes mecânicas, em pé de igualdade com as Belas-Artes. Estavam, assim, criadas as condições favoráveis à $1 .^{\mathrm{a}}$ revolução industrial - desencadeada, em Inglaterra, ainda no terceiro quartel do século XVIII —, passando diversas invenções a ter continuidade nas respectivas inovações. Fazem parte deste processo a utilização da máquina a vapor e de tecnologias que dela vierem a aproveitar, não só na têxtil como noutras indústrias, as inovações introduzidas na exploração mineira e nos transportes, ferroviários, fluviais e marítimos. Diminuiu o período de incubação entre a data dos inventos - de Thomas Newcomen, James Watt (máquina a vapor), James Hargreaves e Richard Arkwight (máquinas de fiação), Edmund Cartwright (tear mecânico), entre outros - e a sua aplicação prática, isto é, a inovação.

O dito movimento inovador - do qual resultaram não só a industrialização como a própria modernização dos outros sectores — prosseguiu e intensificou-se no século XIX. Além da sua expansão geográfica, passando a abranger novas áreas e países, e quantitativa - em tecnologia, empresas e produtos -, registou também consideráveis avanços qualitativos. De facto, nas últimas décadas de Oitocentos, as inovações - da chamada $2 .^{a}$ revolução industrial - situavam-se fundamentalmente nos domínios da electricidade, da Química e do motor de combustão interna, tendo este permitido revolucionar os transportes rodoviários, através da sua motorização.

Lamentavelmente, a história da indústria e da tecnologia regista, de preferência, os nomes dos inventores ou, quando muito, dos inventores-inovadores como Thomas Alva Edison (1847-1931) - , deixando muitas vezes no esquecimento os dos inovadores (não inventores), como patrões, capitães de indústria, empresários, técnicos, etc., agentes imprescindíveis ao processo invenção-inovação, sem os quais numerosos inventos não teriam passado de mera curiosidade enciclopédica.

Aliás, a evolução verificada induziu a que as próprias empresas, a partir de finais do século passado, começassem a fomentar a inovação, criando laboratórios e recorrendo à colaboração de cientistas e de técnicos devidamente especializados. A Siemens, em 1872, revela-se inovadora, sob esta perspectiva, pois terá sido a primeira empresa fabril no mundo a contratar, para o seu serviço, um engenheiro 9 .

Já no século XX, começa a adquirir-se uma noção mais completa do fenómeno inovação, constatando-se que esta ultrapassa, consideravelmente, o âmbito tecnológico. Verifica-se, por exemplo, que ao introduzir-se a racionalização do trabalho - de acordo com os princípios sistematizados por Frederico Winslow Taylor (1856-1915), se obtinham extraordinários aumentos de produtividade. Aquela, patente no trabalho em cadeia, resulta da associação de três inovações complementares: o maquinismo, a continuidade e a organização do trabalho ${ }^{10}$. Henri Ford (1863-1947) foi um dos primeiros empresários a adoptar esta inovação (nas pri- 
meiras décadas do presente século), no fabrico de automóveis, tendo obtido um enorme sucesso. Em 1913, o tempo de construção do carro modelo T havia sido reduzido de 12 para $1 \mathrm{~h}$ e $1 / 4$.

Nos anos 1930, Joseph Schumpeter (1883-1950), ao focar o empresário e a sua função - na sequência das achegas de, entre outros, Werner Sombart e Max Weber -, dedicou-se igualmente ao estudo da inovação, tendo chegado a conclusões ainda hoje actualizadas. Com efeito, foi ele o primeiro a efectuar uma tipologia da inovação e, bem assim, a sublinhar a sua relevância na acção do empresariado. Como recorda François Perroux, para Schumpeter, o empresário «não é o inventor que faz uma descoberta, mas o indivíduo que a saberá introduzir na indústria» ${ }^{11}$.

Consequentemente, Shumpeter supera o conceito restrito de inovação tecnológica, para considerar, como inovações - em seu entender, os fenómenos fundamentais da evolução económica - as diversas "combinações novas dos factores de produção", efectuadas pelos empresários, a saber:

1. Fabrico de um novo produto;

2. Introdução de um novo método de produção;

3. Abertura de um novo mercado;

4. Descoberta de uma nova fonte de matérias-primas;

5. Realização de uma nova organização (por exemplo, a criação de um monopólio) $^{12}$.

Pode acrescentar-se inclusive que, para o autor, a inovação é a principal característica que define o verdadeiro empresário. Esta é também a interpretação de $\mathrm{F}$. Perroux, ao declarar:

«Pouco importa o estatuto jurídico e social do indivíduo: qualquer que ele seja, o indivíduo em questão será empresário ou não, se realizar ou não combinações novas». "Segundo a interpretação de Schumpeter - acrescenta - Henri Ford não se tornou empresário quando, com 43 anos, em 1906, se torna o chefe de uma empresa independente, mas quando, em 1909, começa a fabricar o seu famoso modelo T, rapidamente conhecido sob o nome de automóvel Ford». Foi então que ele aperfeiçoou a divisão do trabalho, criou a linha de montagem e adoptou uma política agressiva de baixa de preços. Por sua vez, Alfred Krup não se transforma em empresário quando, aos 14 anos de idade, se torna proprietário de uma fundição de família, que recebeu de seu pai, ou mesmo quando, em 1848 , ele e o seu sócio se tornam definitivamente proprietários da fábrica, mas sim quando:

- concentra verticalmente as suas fábricas;

- começa a fabricar um novo tipo de círculo de rodas;

- inicia a produção de aço. 
E conclui Perroux:

«Em cada grande capitão de indústria pode-se, pois, averiguar em que momento é que ele se torna empresário, no sentido em que Shcumpeter utiliza a palavra» ${ }^{13}$. Trata-se de uma interessante sugestão para novas pesquisas.

Do ponto de vista teórico, dir-se-ia que os estudos posteriores sobre a inovação - inclusive os mais recentes, baseados em investigação empírica — pouco têm acrescentado ao contributo de Schumpeter. Todavia, ao nível das condições em que "floresce" - ou não - a capacidade inovadora, das consequências da inovação e da sua própria gestão e "manipulação" tem-se avançado bastante, como veremos seguidamente, embora muito haja ainda a fazer.

\section{CONTEXTO E FACTORES DA INOVAÇÃO}

Há factores que favorecem, facilitam ou induzem a inovação - aludindo alguns autores às fontes da inovação - e outros que a bloqueiam, podendo, neste caso, falar-se de resistências à inovação. No que concerne à inovação tecnológica, interroga-se Joel Mokyr:

«Por que é que há sociedades tecnologicamente bem sucedidas e outras não?». E o mesmo autor acrescenta: «Como e quando os inovadores alcançam tais sucessos permanece uma das questões mais interessantes da história económica e da evolução tecnológica». ${ }^{14}$

Uma inovação tecnológica (e mesmo algumas das inovações de outros tipos), bem sucedida, requer sempre a existência de três factores:

- capacidades científicas e tecnológicas;

- a procura do mercado;

- um agente - geralmente uma empresa - que transforme estas capacidades em produtos ou serviços que satisfaçam a procura. ${ }^{15}$

Já foi estimado que de $2 / 3$ a 3/4 das inovações são devidas, inicialmente, a uma definição clara das necessidades do mercado. As restantes são induzidas pela tecnologia ${ }^{16}$, desempenhando a empresa e o empresário, em todas as circunstâncias, um papel decisivo. A propósito, F. Perroux chega mesmo a afirmar:

«A propensão para inovar é função de quatro variáveis principais:

— a forma de remuneração do chefe da unidade;

- o nivel dessa remuneração;

— o nível de informaçã $o^{17}$ de que dispõe o chefe da unidade;

— os estímulos de carácter não aquisitivo ${ }^{18}$, isto é, não decorrentes dum aumento da utilidade material obtida». Contudo, acrescenta o autor:

«Em todas as economias modernas, a propensão para inovar do chefe da unidade de produção depende destas variáveis, mas as instituições [...] 
condicionam [...] cada uma das variáveis e a combinação que todas em conjunto formam ${ }^{19}$ ».

Além das condições científico-tecnológicas, da pressão do mercado e do comportamento empresarial, nos estímulos à inovação incluem-se ainda:

- um clima favorável, ou seja, receptivo à mudança;

- a educação;

- o capital.

Recorde-se que, para certos autores - com os quais concordo inteiramente -, o factor educação (e, bem assim, o capital humano) é mais decisivo que o próprio capital $^{20}$. Em certos casos, da conjugação de vários factores resulta um contexto propício, tendente ao desencadear da inovação. Assim acontece quando se verificam, simultaneamente, as seguintes condições:

- disponibilidade ou facilidade de acesso ao capital;

- procura de mão-de-obra superior à oferta;

- nível de salários/remunerações relativamente elevado ${ }^{21}$.

Num ambiente favorável à inovação, em que esta faça parte do dia-a-dia, cria-se como que uma dinâmica própria, assim caracterizada por David S. Landes, no seu interessante artigo, intitulado «What do Bosses really do?»:

«Cada sucesso convida outros - primeiro, indicando o caminho e, segundo, criando um modelo de permanente eliminação dos bloqueios, com o que se obtêm novas recompensas para a inovação» ${ }^{22}$.

As resistências à inovação - ou, em termos mais gerais, as resistências à mudança - podem verificar-se em vários campos, designadamente na ciência, na arte ou na religião $0^{23}$. No que concerne aos domínios socioeconómico e empresarial - que aqui mais directamente nos interessam -, essas resistências podem partir dos empresários/gestores ou dos operários/empregados, da carência de recursos, humanos ou de capital, ou ainda do próprio ambiente em que se actua.

Quanto aos empresários/gestores, a sua resistência à inovação pode ser motivada por diversos factores, de entre os quais se destacam:

- uma formação insuficiente. Por exemplo, quão longe estamos ainda dos níveis de formação académica de empresários norte-americanos, revelados num estudo recente, segundo o qual:

$-6 \%$ têm o ensino secundário;

- 40\% dispõem de graduação universitária;

$-35 \%$ possuem o Mestrado e

$-13 \%$ o Doutoramento; 
- a carência de informação actualizada, ignorando-se, por vezes, que «a informação é factor de progresso económico nas sociedades do século $\mathrm{XX}{ }^{24}$;

- a exagerada ambição de alguns, deixando-se orientar mais pelos meios lucros, aspectos exclusivamente materiais, etc. - que pelos fins ${ }^{25}$.

Em suma: não obstante uma das funções específicas do empresário consistir, precisamente, em vencer uma série de resistências ${ }^{26}$, ele próprio, em certas circunstâncias, pode oferecer resistência à mudança e à própria inovação.

Quanto aos trabalhadores - operários, técnicos, empregados, etc. —, um dos seus receios deriva do facto de se associar, frequentemente, a inovação à redução da mão-de-obra e, consequentemente, ao aumento da taxa de desemprego. Trata-se de uma questão pertinente e que data, pelo menos, dos ínicios do século XIX - com o movimento chamado «luddismo» que, ao ver nas máquinas concorrentes, fomentava a sua destruição -, mas que ainda mantém certa actualidade. Assim acontece efectivamente, embora, ao longo do século XIX e no século XX, os movimentos de violência anti-tecnológicos tenham sido escassos. É que a competitividade das empresas - forte motivadora da inovação - só de forma muito ténue pode servir para consolar o trabalhador, em vias de perder o seu emprego ${ }^{27}$. Daí que o Grupo de Lisboa - na obra recentemente publicada, sobre os limites à competição - sublinhe:

«A questão é como equilibrar a inovação do processo (a defesa do emprego) e a inovação do produto (ou seja, a criação de emprego)». E acrescenta-se:

«Se o objectivo primário desta inovação é apenas o aumento da competitividade, através da redução de custos, da maior produtividade do trabalho e da melhor qualidade e variedade de produtos e serviços, teremos de admitir que tal inovação tecnológica não servirá o objectivo de pleno emprego de determinado país. Se, pelo contrário, a inovação for utilizada para valorizar as competências e capacidades humanas ou para preencher necessidades não satisfeitas, então, a inovação tecnológica pode dar uma contribuição significativa para a manutenção e crescimento do emprego ${ }^{28}$.

Obviamente que a eliminação de empregos — inerente à «destruição criadora» Schumpeteriana - é frequentemente acompanhada pela criação de novos postos de trabalho, havendo até autores que defendem existir - nos países desenvolvidos - um certo equilíbrio entre os empregos extintos e os criados. Todavia, a questão nem sempre é tão linear, dado poder verificar-se:

- um certo desfasamento temporal, entre os dois momentos;

- os novos empregos exigirem, com frequência, formação e competências mais complexas do que as requeridas pelos empregos entretanto desaparecidos. A formação contínua, o aprender a aprender e os cursos de reciclagem ajudam a minorar o problema. 
A carência de recursos, por seu turno, constitui igualmente factor favorável às resistências à inovação, já que, em tais circunstâncias, a rotina e a tradição são susceptíveis de imperar. Passa por aqui um certo anquilosamento tecnológico e organizativo de muitas empresas, as quais, se não conseguirem alterar aquela tendência, estarão condenadas ao fracasso, a curto ou médio prazo.

Por último, acerca do ambiente propício às resistências à inovação, trata-se não só de condições materiais mas da própria mentalidade. ${ }^{29}$.

Analisando os motivos patentes nas obras daqueles que denomina «intelectuais tecnológicos», Joel Mokyr — num artigo intitulado "Technological Inertia in Economic History" - enuncia os seguintes:

- aversão ao risco elevado, dado que a mudança tecnológica envolve actividades ainda não experimentadas;

- receio de que a inovação reduza a eficiência económica, distorcendo a localização de recursos;

- correlação das mudanças tecnológicas com outros fenómenos - políticos e sociais -, pelo que a crítica à tecnologia tem estado, por vezes, associada ao pacifismo;

- a inovação tecnológica é considerada - pelos referidos autores - como parte do "laissez-faire" industrialista, contribuindo para a progressiva deterioração da Humanidade ${ }^{30}$.

Analisados o significado da inovação e alguns dos factores que a estimulam ou bloqueiam, vejamos seguidamente como fazer dela um útil instrumento da estratégia empresarial.

\section{COMO GERIR A INOVAÇÃO PELA VIA DO SUCESSO?}

A capacidade de, não só aceitar a mudança mas sobretudo de a promover e incrementar é, hoje, uma necessidade praticamente vital das empresas. Como destacam os autores de L'art du management européen, «para enfrentar com sucesso a vida dos negócios, os gestores deverão desenvolver a sua capacidade de mudança ${ }^{31}$. Por esse motivo, a inovação, até hà pouco um fenómeno esporádico, transformou-se num instrumento de uso comum pelas empresas de sucesso ou que tudo fazem para o alcançar. Assim, a inovação - ou, se se preferir, a mudança ${ }^{32}$ ou a novidade - torna-se banal e permanente, sendo já difícil detectar picos no respectivo processo ${ }^{33}$.

Sendo a inovação - como já referi anteriormente - a função que melhor caracteriza o verdadeiro empresário ou gestor, todos os que têm a responsabilidade de dirigir as empresas devem, de algum modo, transformar-se em "gestores 
da inovação". Também neste campo as instituições de ensino têm uma palavra a dizer. Sobre assunto já foi salientado:

«A dimensão crescente da transformação técnica atribui à política de ensino um outro dever importante: formar não só criadores da ciência e da tecnologia, mas igualmente os gestores da mutação tecnológica» ${ }^{34}$.

Além da formação académica inicial — nos domínios da gestão e afins -, há que realçar os cursos de pós-graduação, as acções de formação, seminários ou outros cursos breves, bem como a auto-aprendizagem, ao longo de toda a vida do indivíduo. Dado o ritmo acelerado das transformações operadas - já acima mencionado - , a formação inicial, em vez de ponto de chegada, constitui actualmente um ponto de partida, ainda que da maior relevância. Além disso, a própria experiência - em "lidar" com a inovação, no caso vertente — assume importante significado, quer em relação aos êxitos, quer mesmo aos eventuais insucessos. A aprendizagem através do erro - muito valorizada, por exemplo, no sistema de ensino norte-americano e na própria gestão empresarial americana e japonesa pode desempenhar, igualmente, um papel positivo ${ }^{35}$.

Também uma adequada informação - vasta, diversificada e, sobretudo, actualizada - desempenha um lugar relevante no "uso" da inovação. James Harold vai mesmo mais longe, ao afirmar, referindo-se a banqueiros:

“A sua capacidade inovadora, se é possível detectá-la, liga-se à sua competência para acumular, avaliar e disseminar informação económica" ${ }^{36}$. Por sua vez Kirton, tomando igualmente como referência a capacidade para inovar, distribui os gestores por dois grupos, a que chama adaptadores inovadores.

a) Adaptadores: «os que são capazes de iniciar a mudança e de aperfeiçoar o sistema corrente, mas que fracassam consistentemente por não verem possibilidade fora do sistema existente».

b) Inovadores: “"homens de ideias", capazes de gerar mudança mais radical, mas que têm dificuldade em ver as suas ideias aceites e assim não são bem sucedidos na sua concretização». Eu preferiria dizer, de forma menos radical, que nem sempre são bem sucedidos na sua acção.

E acrescenta o autor:

«Em geral, os adaptadores tendem a trabalhar dentro do sistema existente, enquanto os inovadores contestam-no e mudam-no [...]. Um adaptador pode ser bastante original (ou criativo), mas tenderá para um alto nível de eficiência (isto é, para o método e a precisão) e será algo conformista, pelo que a sua criatividade ficará confinada dentro do sistema». Por seu turno, «o inovador, com altos parâmetros de originalidade mas baixos em conformidade e eficiência, sentir-se-á menos constrangido pela perspectiva tradicional dos problemas, e assim será mais provável que mude o sistema existente» ${ }^{37}$. 
À interessante análise de Kirton - uma das achegas mais válidas para o estudo da inovação post - Schumpeter - eu apenas acrescentaria que, na maior parte dos casos, em vez de se verificar uma dicotomia tão acentuada, o mesmo empresário ou gestor revelará capacidade adaptativa e inovadora, ainda que, obviamente em doses diversas. Por tal motivo, uma parte daqueles situar-se-á como que numa posição intermédia, ou, quando muito, apresentará mais tendência para a adaptação ou, ao invés, para a inovação.

Sendo a inovação um meio - para alcançar a excelência e o sucesso -, não pode ser vista de forma isolada, no âmbito da actividade empresarial. Assim, dado que a acção inovadora - como, aliás, a própria ciência e a tecnologia -, em si mesma, não pode classificar-se de boa ou máa ${ }^{38}$, pois tudo depende do modo como for utilizada a dos objectivos a atingir, faz sentido relacioná-la com a ética empresarial.

\section{INOVAÇÃO E ÉTICA EMPRESARIAL}

Ser empresário ou gestor, nos anos 90 , pressupõe ou exige uma sólida formação - a qual deve ser permanentemente actualizada —, inclusive no domínio das ciências humanas e sociais. A propósito, já se escreveu:

"É preciso aprender a aprender e prosseguir este caminho durante toda a vida de adulto. Não bastará iniciar-se em novas tarefas, novos domínios e novas especialidades para efectuar transformações; é preciso também preparar-se para ter acesso a outros níveis de conhecimento em domínios fundamentais, tais como as ciências humanas ou as matemáticas ${ }^{39 "}$.

É que, só com uma formação, tão completa quanto possível, poderão ser equacionados problemas de grande complexidade, sobre os quais o empresário e o gestor não poderão deixar de reflectir. A título de exemplo, podem mencionar-se os que se seguem:

- funções e objectivos - secundários e essenciais — da actividade empresarial;

- o papel da empresa no contexto socioeconómico, político e cultural, a nível local, regional, nacional e internacional;

- as assimetrias no desenvolvimento e as suas possíveis repercussões, a médio e a longo prazo;

- o tipo de recursos a utilizar e de artigos a produzir, de modo a que satisfaçam as necessidades mas não ajudem a destruir o Planeta;

- como aumentar substancialmente a qualidade dos produtos e serviços, mantendo certo poder de competitividade;

- como fomentar a adopção de normas de conduta éticas, no seio das empresas e nas relações destas com o exterior. 
Não sendo possível, nas presentes circunstâncias, analisar todas estas e outras questões pertinentes, limitar-me-ei a tecer certas considerações sobre algumas delas. Procurarei evidenciar o facto de a inovação - a despeito do seu enorme interesse - não dever ser adoptada a qualquer preço, pois, como em tudo na vida, há circunstâncias, valores e princípios que deverão servir de bússola aos respectivos agentes, no acto de inovar.

Começando pelos objectivos da empresa - e, em grande medida, dos próprios empresários -, trata-se de uma questão já clássica, mas que tem vindo ultimamente a ser requacionada, graças aos contributos da Psicologia, da Sociologia e da Cultura de Empresa. Sobre o assunto, sublinham os autores da Arte da gestão europeia, obra já anteriormente citada.

«Os dirigentes europeus consideram o lucro como um dos objectivos essenciais da empresa, e não a sua finalidade. O lucro é um meio ao serviço de uma razão de ser mais profunda ${ }^{40}$.

Esta também passa, como é sabido, pela função social da empresa, pela realização dos que se lhe dedicam, pelo desejo de alcançar poder por parte dos seus líderes, pela intervenção no processo de desenvolvimento, etc. Como já foi sublinhado, «gerir tendo em vista apenas o lucro é como jogar ténis de olho no marcador e não na bola» ${ }^{41}$.

Ao invés do que tem vindo a suceder frequentemente desde os anos 1970 - em que a inovação tem visado quase exclusivamente o aumento da produtividade e o reforço da competitividade, com o sacrifício de certos grupos sociais mais vulneráveis ${ }^{42}$ - numa lógica sobretudo de crescimento, há que inverter a tendência, actuando mais no sentido do desenvolvimento. De facto, este não se consegue só através da progressão de alguns índices económicos, mas pela melhoria do nível de vida e do bem-estar das pessoas, em todos os domínios. Reforçando o que se acaba de expor acerca da superioridade do desenvolvimento sobre o crescimento, pode ler-se num artigo sobre o tema:

«O desenvolvimento concerne às modificações mais profundas, que são a própria condição de um crescimento harmonioso; [...] ele visa produzir uma mudança nas estruturas mentais e nos hábitos sociais de uma população, de forma a colocá-la em condições de aproveitar plenamente do progresso técnico e dos seus benefícios» ${ }^{43}$.

Acerca das assimetrias no desenvolvimento, não deixa de ser preocupante a evolução verificada nos últimos dois séculos e meio. Assim, enquanto nos inícos da revolução industrial a diferença do rendimento "per capita", entre os países mais ricos e mais pobres, era de 5 para 1, actualmente o fosso entre a nação industrializada mais rica - a Suíça - e o país não industrializado mais pobre - Moçambique - é de 400 para $1^{44}$.

No que se refere à gestão ética, trata-se de uma temática que tem vindo a merecer, nos últimos tempos, uma crescente atenção. $O$ despertar dos estudiosos para o assunto seguiu-se à "descoberta" da empresa, como objecto de estudo, e ao reconhecimento do papel do empresário/gestor, na economia e na sociedade contem- 
porâneas. Por outro lado, está também relacionado com um certo desencanto, por parte daqueles que acreditavam que a ciência e a tecnologia, sem mais, eram suficientes para solucionar todos os problemas com que o homem de debate. Por último, o egoísmo, a ganância desmedida, a corrupção, a competitividade desenfreada e o consumismo induzem a que se reflicta sobre estas questões.

Daí o formularem-se perguntas cruciais, como esta:

«Será possível hoje em dia ser-se competitivo e ao mesmo tempo agir de uma forma ética e honesta?». Um consultor responde:

«Sim [...]. A nova liderança tem de criar uma atmosfera positiva, produtiva, baseada na ética» ${ }^{45}$.

Em certos casos, inovação e ética encontram-se expressamente associadas. Por exemplo, a "Nucor Steel", empresa norte-americana, produtora de aço, estabeleceu, como normas de ideias inovadoras, apenas as seguintes:

- a ideia deve relacionar-se com o aço;

- não deve violar qualquer lei;

- não pode ser imoral. ${ }^{46}$

Uma perspectiva também interessante relaciona-se com a gestão numa diversidade de culturas - em sentido genérico e empresarial - e no respectivo enquadramento ético. Após um período de algum fascínio, por parte de estudiosos è gestores europeus, pelos modelos de gestão de outras áreas geográficas e culturais designadamente japonês e, de certo modo, também norte-americano - , começa a reflectir-se igualmente sobre as virtualidades da gestão europeia. Esta, como se sabe, é marcada ou influenciada por uma cultura riquíssima, cujos marcos milenares mais notórios remontam às culturas greco-latina e judaico-cristã. Neste sentido, afirmam os autores de L'art du management européen, já acima citados:

«Indiscutivelmente, um modelo europeu de gestão está em vias de vir à luz do dia. Eis as suas características essenciais», que passo a sintetizar:

- adaptação à diversidade internacional;

- responsabilidade social;

- negociação interna;

- respeito pelos indivíduos;

- sistemas de gestão menos formalistas;

- orientação equilibrada, entre a produção, por um lado, e o marketing e serviço do cliente, por outro ${ }^{47}$.

Os autores falam ainda de uma «nova Renascença» e de humanismo no modelo europeu de gestão, acrescentando:

«Qualquer que seja a sua admiração pela ciência e pela tecnologia moderna, os Europeus julgam que o progresso deve estar ao serviço do homem, e não o inverso» ${ }^{48}$. 
Quanto a este último aspecto, trata-se, no fundo, de retomar o pensamento de F. Perroux que, já há cerca de três décadas, afirmava:

«O projecto humano prevalece sobre o equilíbrio mecanicista, do qual o homem é praticamente banido» ${ }^{49}$.

Positivo é também o facto de se ter começado a pensar na elaboração de instrumentos que ajudem a operacionalizar a avaliação de comportamentos éticos. Por exemplo, no livro intitulado $O$ poder da gestão ética - acessível em versão portuguesa - os autores, de acordo com a premissa segundo a qual «não existe uma forma certa de fazer uma coisa errada ${ }^{50}$, apresentam o chamado QUESTIONÁRIO ÉTICO. Este, embora muito simples, pode ser de utilidade, face a assuntos de difícil solução. Integram-no as seguintes questões:

1. É legal?

2. É equilibrado?

3. Como me vou sentir comigo próprio? ?1 $^{51}$

Reforçando o papel que, neste processo, compete à consciência de quem aplica o questionário - o que, em última análise, nos remete para a importância da formação, necessariamente acompanhada pela transmissão e interiorização de valores -, transcrevem a seguinte afirmação, de um lendário treinador de basquetebol:

«Não existe melhor travesseiro do que uma consciência limpa» ${ }^{52}$.

Como se pode concluir do que acabo de expor, inovar é uma questão da maior importância - para a Humanidade, para o homem, em geral, e para as próprias empresas -, embora igualmente complexa. Múltiplos factores condicionam a inovação e as suas repercussões fazem-se sentir a vários níveis. Pode-se acrescentar, inclusivamente, que ela é imprescindível. Já Francis Bacon (1561-1622), ao focar as «inovações» - nos Ensaios -, notava:

«Cada remédio é certamente uma inovação; e aquele que não quiser aplicar novos remédios deve esperar por novos males; porque o tempo é o grande inovador» ${ }^{53}$.

Problema complexo, sem dúvida, mas que vai ao encontro de uma das principais características do ser humano que, como notou um poeta latino, está «ávido de coisas novas " ${ }^{54}$. Além disso, hoje podemos beneficiar das experiências dos que nos antecederam - registadas pela história - , podendo assim comportarmo-nos como "anões às costas de gigantes" 55 . Por tais motivos, o actual contexto da nossa civilização já foi comparado a uma caixa de presentes, cheia de dificuldades contando-se, entre elas, o próprio uso adequado da inovação -, mas em que o último presente é, felizmente, a esperança $a^{56}$. 


\section{NOTAS}

* O texto que ora se publica, anotado, foi inicialmente apresentado como Oração de Sapiência, no Pólo de Viseu do Centro Regional das Beiras da Universidade Católica Portuguesa, em 14.01.1995.

.' «Inovação», G. Thimes e Agnés Lempereur (dir.), Dicionário Geral das ciências humanas (trad. do francês), Lisboa, Ed. 70, 1984, p. 504.

2 Peter F. Drucker, Inovação e gestão (trad. do inglês), Lisboa, Ed. Presença, 1986, p. 46.

${ }^{3}$ Ver, por exemplo, as seguintes obras: Innovation rechnologique et civilization (XIX-XX siècles), Paris, CNRS, 1989; Christian Le Bas, Les Innovations technologiques induites. Une analyse critique, Grenoble, Service de Reproduction de Theses de l'Université des Sciences Sociales de Grenoble (tese de doutoramento, apresentada em 1978, posteriormente publicada, em versão remodelada, Paris, Ed. Economica, 1982); Conditions du succèss de l'innovation technologique, Paris, Organisation de Coopération et de Développement Economiques, 1971; Les aspects internationaux de l'innovation technologique. Actes du symposium de politique scientifique (Paris, France, 7-9 septembre 1970), Paris, UNESCO, 1972.

${ }^{4}$ P. F. Drucker, idem, p. 43.

${ }^{5}$ Conditions du succès de l'innovation technologique, p. 21.

${ }^{6}$ P. Drucker, op. cit., p. 45.

${ }^{7}$ P. Drucker, op. cit., p. 147.

${ }^{8} \mathrm{P}$. Drucker, ibidem.

${ }^{9}$ Tratou-se de Hefner-Alteneck (P. Drucker, op. cit., p. 181).

${ }^{10}$ Innovation technologique et civilisation, p. 135 e 137.

" François Perroux, "Introdução à obra de Joseph Schumpeter, Théorie de l'évolution économique. Recherches sur le profit, le crédit, l'intérêt et le cycle de la conjuncture, Paris, Libraire Dalloz, 1935, p. 93-94.

12 J. Schumpeter, idem, p. 93 e 319.

${ }^{13}$ J. Schumpeter, idem, p. 94 e 96-97.

14 Joel Mokyr, «Technological inertia in economic history», The Journal of Economic History, vol. 52,1992, n. $^{\circ} 2$, p. 325 e 327.

${ }^{15}$ Conditions du succès de l'innovation technologique, p. 11-12.

${ }^{16}$ Idem, p. 12.

${ }^{17}$ Que o autor especifica, em nota: «Sobre as condições da tarefa a realizar, sobre o meio da unidade, sobre as prováveis modificações deste meio durante um período" (François Perroux, A economia do século XX [trad. do francês], Livraria Morais Editora, 1967, p. 677, nota 3).

${ }^{18}$ F. Perroux esclarece: «os estímulos de carácter não aquisitivo pertencem ao domínio dos móbeis schumpeterianos (vontade de poder, espírito desportivo, estética da produção, etc.)» (F. Perroux, ob. cit., p. 678).

${ }^{19}$ F. Perroux, ob. cit., p. 677-678.

${ }^{20}$ Conditions du succès de l'innovation technologique, p. 11-12

${ }^{21} \mathrm{Ch}$. Lebas, Les innovations technologique induites, p. 42.

22 David S. Landes, «What do Bosses really do?», The Journal of Economic History, vol. XLVI, 1986, n. ${ }^{\circ}$, p. 615.

23 J. Mokyr, op. cit., p. 327.

${ }^{24}$ Reg Jennings et al., Business Elites. The Psychology of entrepreneurs and intrapreneurs, Londres, Routlege, 1994, p. 71.

${ }^{25}$ F. Perroux, op. cit., p.487.

${ }^{26}$ Voltarei ao assunto, no ponto 4 deste trabalho.

${ }^{27}$ A propósito, é muito elucidativa a seguinte legenda de uma ilustração, publicada em The 
o seu contributo para manter a América um país globalmente competitivo» (apud Grupo de Lisboa, Limites à competição, Mira - Sintra - Mem Martins, Publ. Europa-América, 1994, p. 73).

${ }^{28}$ Grupo de Lisboa, idem, p. 71-72.

${ }^{29}$ Cfr. Kurgan-van Hentenryk, «Belgique. L'innovation technologique facteur de changement. Résistance au adaptation, reflect mentalités», Innovation technologique et civilisation, p. 73-88.

${ }^{30}$ Cfr. J. Mokyr, op. cit., p. 333-335.

${ }^{31}$ Helen Bloom et al., L'art du management européen, Paris, Les Editions d'Organisation, 1994, p. 120.

${ }^{32}$ F. Perroux, ob. cit., p. 677-678.

${ }^{33}$ Paul Klep e Eddy Van Cauwenberghe (eds.), Entrepreneurship and the transformation of the economy (10 $0^{\text {th }}-20^{\text {th }}$ centuries). Essays in Honour of Herman Van der Wee, Leuven University Press, 1994, p. 306; Construir as vantagens competitivas de Portugal (Monitor Company, sob a direcção de Michel Porter), 2." ed., Lisboa, Ed. do Forum para a Competitividade, 1994, p. 18.

${ }^{34}$ Conditions du succés de l'innovation technologique, p. 150. A formação escolar, em geral, também prepara o indivíduo para lidar com uma grande variedade de situações com que presumivelmente se irá deparar pela vida fora (Reg Jennings et al., op. cit., p. 70).

${ }^{35} \mathrm{H}$. Bloom et al., op. cit., p. 123.

${ }^{36}$ Entrepreurship and the transformation of the economy, p. 202.

${ }^{37}$ M. J. Kirton, "Adaptatores and innovators: a description and a mesure", Journal of Applied Psychology, 61, 1976, n. ${ }^{\circ}$ 5, p. 622-629, apud Reg Jennings et al., Business elites. The Psychology of entrepreneurs, Londres, Routledge, 1994, p. 97-100.

${ }^{38}$ Cfr. David S. Landes, op. cit., p. 620.

${ }^{39} \mathrm{H}$. Bloom et al., op. cit., p. 114.

${ }^{40} \mathrm{H}$. Bloom et al., op. cit., p. 51.

${ }^{41}$ Kenneth Blanchard e Norman Vincent Real, O poder da gestão ética (trad. do inglês), Lisboa, Difusão Cultural, 1993, p. 98.

42 Grupo de Lisboa, Limites à competição, p. 149-150.

${ }^{43}$ Pierre Chaunu, «Croissance ou développement (?). A propos d'une véritable histoire économmique de l'Amérique latine aux XIXe et XXe siècles», Revue d'Histoire, 496, 1970, p. 359.

${ }^{44}$ Entrepreneurship and the transformation of the economy, p. 300.

${ }^{45} \mathrm{~K}$. Blanchard e N. V. Peale, op. cit., p. 78 e 81.

${ }^{46}$ Francis J. Aguilar, Managing corporate ethics. Learning from America's ethical companies how to supercharge business performance, Oxford University Press, 1994, p. 149.

${ }^{47} \mathrm{H}$. Bloom et al., op. cit., p. 16-17.

${ }^{48} \mathrm{H}$. Bloom et al., op. cit., p. 21 e 27-28.

${ }^{49} \mathrm{~F}$. Perroux, A economia do século XX, p. 21.

${ }^{50}$ K. Blanchard e N. Vincent Peale, op. cit., p. 19.

${ }^{51}$ K. Blanchard e N. Vincent Peale, op. cit., p. 20-24.

${ }^{52}$ K. Blanchard e N. Vincent Peale, op. cit., p. 25.

${ }^{53}$ Francis Bacon, Ensaios, Lisboa, Guimarães \& C", Editores, 1952, p. 124.

54 «Um poeta latino chamou ao ser humano "rerum novarum cupidus" (ávido de coisas novas)». A gestão empresarial deverá tornar todos os gestores das organizações estabelecidas "rerum novarum cupidus" (P. Drucker, Inovação e gestão, p. 164).

55 Imagem conhecida, atribuída a um monge medieval e também usada por Isaac Newton (1642-1727), ao declarar: «Se fui capaz de ver mais longe foi porque me apoiei nos ombros de gigantes» (K. Blancherd e N. V. Peale, $O$ poder da gestão ética, p. 125).

${ }^{56}$ Entrepreneurship and the transformation of the economy, p. 308. 


\section{BIBLIOGRAFIA}

AGUILAR, Francis, J., 1994, Managing corporate ethics, Learning from America's ethical companies how to supercharge business performancel, Nova Iorque-Oxford, Oxford University Press.

Aspects (Les) internationaux de l'inovation technologique. Actes du Symposium de politique scientifique (Paris, France, 7-9 septembre 1970), 1972, «Études et documents de politique scientifique», $\mathrm{n}^{\circ}$ 26, Paris, UNESCO.

BACON, Francis, 1952, Ensaios, Lisboa, Guimarães \& C. .

BLANCHARD, Kenneth e PEALE, Norman Vincent, 1993, O poder da gestão ética (trad. do inglês), Lisboa, Difusão Cultural.

BLOOM, Helen et al., 1994, L'art du management européen (trad. do inglês), Paris, Les Éditions d'Organisation.

BOUCHIKI, Hamid e KIMBERLY, John, 1994, Entrepreneurs et gestionnaires. Les clés du management entrepreneural. Prefácio de Michel Berry, Paris, Les Éditions d'Organisation.

CHAUNU, Pierre, 1970, «Croissance ou développement (?). A propos d'une véritable histoire écnonomique de l'Amérique latine au $\mathrm{XIX}^{\mathrm{e}}$ et $\mathrm{XX}^{\mathrm{e}}$ siècle», Revue Historique, 496, p. 357 -374 .

Conditions du succès de l'innovation technologique, 1971, Paris, Organisation de Coopération et de Développement Économiques.

DRUCKER, Peter F., 1986, Inovação e gestão. Uma nova concepção de estratégia de empresa (trad. do inglês), Lisboa.

Grupo de Lisboa, 1994, Limites à competição, Mira-Sintra-Mem Martins, Publ. Europa-América.

Innovation technologique et civilisation (XIX ${ }^{e}-X X^{e}$ siècles), 1989, Paris, CNRS.

Inovação para jovens empresários, 1989, Lisboa, Instituto de Apoio às Pequenas e Médias Empresas e ao Investimento/Instituto da Juventude.

JENNINGS, Reg et al., 1994, Business elites. The psychology of entrepreneurs and intrapreneurs, Londres-Nova Iorque, Routledge.

KLEP, Paul e CAUWENBERG, Eddy Van, 1994, Entrepreneurship and the transformation of the economy (10th-20th centuries). Essays in Honour of Herman der Wee, Leuven University Press.

LANDES, David, S., 1986, "What do Bosses really do?», The Journal of Economic History, vol. XLVI, 1986, n. ${ }^{\circ}$ 3, p. 585-623.

LE BAS, Christian, 1978 (?), Les innovations technologiques induites. Une analyse critique, Service de Reproduction des Theses de l'Université des Sciences Sociales de Grenoble (tese de doutoramento em Ciências Económicas, apresentada à Universidade de Lyon II, em 1978).

LE BAS, Christian, 1982, Economie des innovations techniques. Prefácio de Gilbert AbrahamFrois, paris, Economica.

MOKYR, Joel, 1992, «Technological inertia in economic history», The Journal of Economic History, vol. 52, 1992, n. ${ }^{\circ}$ 2, p. 325-338. 
PERROUX, François, 1967, A economia do século XX (trad. do francês), Lisboa, Livraria Morais Editora.

PETERS, Tom, 1994, «Inovação ou morte», Exame/Executive Digest, ano 1, n. ${ }^{\circ}$ 0, p. 38-40.

PORTER, Michael (Monitor Company, sob a dir. de ...), Construir as vantagens competitivas de Portugal, 1994, Lisboa, ed. do Forum para a Competitividade.

THINES, G. e LEMPEREUR, Agnés (dir. de), 1984, «Inovação», Dicionário Geral das Ciências Humanas (trad. do francês), Lisboa, Ediçōes 70.

VICENTE, Camarinha, 1980, Inovação participativa por objectivos ne empresa e fora dela, "Congresso 80", tema 1, comunicação 12, Ordem dos Engenheiros.

WEBER, Max, 1983, A ética protestante e o espírito do capitalismo (trad. do alemão), Lisboa, Editorial Presença. 